\title{
Influence of galacto-oligosaccharide mixture (B-GOS) on gut microbiota, immune parameters and metabonomics in elderly persons
}

\author{
Jelena Vulevic ${ }^{1 *}$, Aleksandra Juric ${ }^{2}$, Gemma E. Walton ${ }^{2}$, Sandrine P. Claus ${ }^{2}$, George Tzortzis ${ }^{1}$, \\ Ruth E. Toward ${ }^{2}$ and Glenn R. Gibson ${ }^{2}$ \\ ${ }^{1}$ Clasado Research Services, Science and Technology Centre, Reading, UK \\ ${ }^{2}$ Department of Food and Nutritional Sciences, The University of Reading, Reading, UK
}

(Submitted 28 March 2014 - Final revision received 31 March 2015 - Accepted 29 April 2015 - First published online 28 July 2015)

\begin{abstract}
It is recognised that ageing induces various changes to the human colonic microbiota. Most relevant is a reduction in bifidobacteria, which is a health-positive genus. Prebiotics, such as galacto-oligosaccharides (GOS), are dietary ingredients that selectively fortify beneficial gut microbial groups. Therefore, they have the potential to reverse the age-related decline in bifidobacteria and modulate associated health parameters. We assessed the effect of GOS mixture (Bimuno (B-GOS)) on gut microbiota, markers of immune function and metabolites in forty elderly (age 65-80 years) volunteers in a randomised, double-blind, placebo (maltodextrin)-controlled, cross-over study. The intervention periods consisted of 10 weeks with daily doses of $5.5 \mathrm{~g} / \mathrm{d}$ with a 4 -week washout period in between. Blood and faecal samples were collected for the analyses of faecal bacterial populations and immune and metabolic biomarkers. B-GOS consumption led to significant increases in bacteroides and bifidobacteria, the latter correlating with increased lactic acid in faecal waters. Higher IL-10, IL-8, natural killer cell activity and C-reactive protein and lower IL-1 $\beta$ were also observed. Administration of B-GOS to elderly volunteers may be useful in positively affecting the microbiota and some markers of immune function associated with ageing.
\end{abstract}

Key words: Galacto-oligosaccharides: Prebiotics: Microbiota: Elderly: Immunity

Worldwide, the elderly population is expanding faster than any other age group and has been seen to double since 1980 (WHO). While a growing ageing population is indicative of advances in global health, this population is a vulnerable group in terms of disorder. This has both medical and economic impacts. Therefore, strategies to promote healthy ageing are desirable. During the ageing process, certain changes in the immune system have been observed. The process often referred to as immunosenescence has been characterised by deterioration of both the adaptive and innate immune responses ${ }^{(1)}$.

Changes to the ageing immune system often include reduced thymic T-cells, resulting in a substantial decrease in antigen-specific immunity ${ }^{(2)}$. There are fewer bone marrow early progenitor B cells ${ }^{(3)}$ and an accumulation of functionally incompetent memory cells ${ }^{(4)}$. Thus, a reduction in antigen recognition may be observed with ageing. More recently, attention has turned to so-called 'inflammaging', the development of a low-grade chronic proinflammatory state. Such changes are characterised by raised levels of IL- 6 and TNF, with reduced $\mathrm{IL}-10^{(5)}$. A similar inflammatory status has been observed in diabetes, some vascular diseases and oesteoporosis. As such, reducing these inflammatory changes may positively have an impact on a range of conditions associated with ageing ${ }^{(6,7)}$.

The colonic microbial community has also been seen to change with ageing. The most consistent observation is a decline in the beneficial genus Bifidobacterium spp. ${ }^{(8-10)}$. Other reports have suggested lower levels of known butyrate producers, Clostridium cluster XIVa and Faecalibacterium prausnitzii $^{(11,12)}$. The human intestinal tract, particularly the colon, is home to a vast array of diverse bacteria that interact and develop along with the host. Recent studies have provided evidence that the microbiota and associated metabolites may modulate certain immunological signalling pathways ${ }^{(13)}$. One strategy for modulating immune system changes is, therefore, through specific targeting of gut microbial changes.

Prebiotics have been used to alter the gut microbiota through the selective stimulation of bacteria in the intestinal tract that are deemed positive to human health ${ }^{(14)}$. Prebiotics, such as inulin and GOS (galacto-oligosaccharides), often target the Bifidobacterium genus. This is related to the size and

Abbreviations: B-GOS, Bimuno-GOS mixture; CRP, C-reactive protein; GOS, galacto-oligosaccharides; LDH, lactate dehydrogenase; NK, natural killer; PBMC, peripheral blood mononuclear cells; RPMI, Roswell Park Memorial Institute; sIgA, secretory IgA.

*Corresponding author: J. Vulevic, email jvulevic@yahoo.com 
structure of these prebiotics. We have previously researched a GOS product manufactured by reverse $\beta$-galactosidase synthesis from enzymes in Bifidobacterium bifidum NCIMB $41171^{(15)}$. This B-GOS (Bimuno-GOS mixture) has been observed to support the growth of bifidobacteria in young, older, overweight humans and in patients with irritable bowel syndrome ${ }^{(16-19)}$. Furthermore, animal models have shown B-GOS to exhibit anti-infection mechanisms against Salmonella enterica Typhimurium ${ }^{(20)}$, and positive effects on the immune response in older and overweight individuals have also been observed ${ }^{(17,18)}$. While interaction of the gut microbiota with the immune system is becoming more recognised, there is a need to further elucidate whether altering the microbiome by dietary intervention can influence immunosenescence. As such, the present study tested B-GOS as a prebiotic in elderly persons, while also investigating immunological parameters and metabonomic profiles.

\section{Materials and methods}

Unless otherwise stated, all chemicals and reagents were obtained from Sigma-Aldrich Company Limited. Fluorescent probes, the K562 cell line and cell culture media, and supplements were also obtained from Sigma-Aldrich Company Limited.

\section{Subjects and study design}

A total of forty elderly volunteers (25 women and 15 men; average age 70.4 (SD 3.8) years; range 65-80 years) were enrolled into this randomised, double-blind, placebo-controlled, cross-over study. Using MGH Biostatistics Software, thirty-four volunteers were estimated to provide $90 \%$ statistical power based on a cross-over design and an average change of 13.5 (SD 26) for natural killer (NK) cell activity, and forty volunteers were estimated to provide $90 \%$ statistical power based on a cross-over design and an average log change of 0.26 (SD 0.55) for Bifidobacterium spp. using data from a previous trial with B-GOS in elderly ${ }^{(20)}$. Thus, to cover for both variables, forty volunteers were enrolled into the trial. Trial exclusion criteria included use of antibiotics 3 months before commencing the study; regular use of prebiotic, probiotic or synbiotic supplements 2 weeks before the study; use of immunosuppressive or anti-inflammatory drugs or any drugs affecting intestinal mobility; former participation in another study involving prebiotic, probiotic or synbiotic preparations or other investigational drugs 6 months before the study; and history or evidence of any intestinal disorders. The present study was conducted according to the guidelines laid down in the Declaration of Helsinki, and all procedures involving human subjects were approved by the University of Reading Ethics and Research Committee. Written informed consent was obtained from all volunteers, and they were assessed before the beginning of the trial for good general health. The study was registered at clinicaltrials.gov (identifier no. NCT01303484).

Volunteers were randomly assigned using an allocation ratio of 1:1 to one of two groups: one started the trial with the placebo (maltodextrin) and the other with B-GOS, with both compounds provided in powder form $(5.5 \mathrm{~g})$ and supplied by Clasado Limited. Doses of both products have been previously used in human subjects ${ }^{(16-19)}$. Composition of the B-GOS mixture is presented in Table 1. Subjects were asked to reconstitute the contents of the sachets immediately before consumption by mixing the powder with water and to consume the product every day at approximately the same time. They consumed the products for 10 weeks, followed by a 4-week washout period, before switching to the other intervention for the final 10 weeks. Volunteers were required to visit the University of Reading on eight separate occasions during this period. Their blood pressure and weight were recorded and faeces collected at each visit ( 4 weeks before the beginning; on day 0; and after 5, 10, 14, 19, 24 and 28 weeks). During all visits (except 4 weeks before the beginning), blood was sampled and the use of any medication (including vitamin-mineral supplements) and adverse events were recorded. In addition, subjects were asked to confirm their compliance with, or deviation from, the study protocol and to keep daily diaries recording bowel movements, stool consistency and incidences of abdominal pain, flatulence and bloating.

\section{Diet diary analysis}

Habitual diet of volunteers was assessed by pre-validated, 4-d food diaries (two weekends and two weekdays) before the beginning of the study and once during each intervention period. Information collected in the food diaries was analysed using a nutritional software package (Dietplan 6; Forestfield Software Limited).

\section{Preparation and collection of faecal samples}

Faecal samples were collected, diluted, homogenised and used to enumerate gut bacteria by fluorescent in situ hybridisation, as described previously ${ }^{(18)}$. A portion of each faecal sample was removed before dilution and freeze-dried to determine dry weight and for NMR-based metabolite analyses.

Table 1. Composition of galacto-oligosaccharide mixture (B-GOS) including degree of polymerisation (DP) and saccharide linkages, as percentage of the galacto-oligosaccharide content ${ }^{\star(14)}$

\begin{tabular}{lc}
\hline & B-GOS $(n)$ \\
\hline DP & \\
DP 2 & 52 \\
DP 3 & 26 \\
DP 4 & 14 \\
DP 5 & 8 \\
Linkages & \\
$\beta 1 \rightarrow 3$ & 26 \\
$\beta 1 \rightarrow 4$ & 23 \\
$\beta 1 \rightarrow 6$ & 51 \\
Average molecular weight (kDa) & 496.8 \\
\hline
\end{tabular}

* The galacto-oligosaccharide content of B-GOS was $48 \%$ (w:w). 


\section{Bacterial enumeration using fluorescent in situ hybridisation}

Differences in bacterial populations were assessed using fluorescent in situ hybridisation analysis with oligonucleotide probes designed to target specific diagnostic regions of $16 \mathrm{~S}$ rRNA, as previously described ${ }^{(18)}$. The probes used were

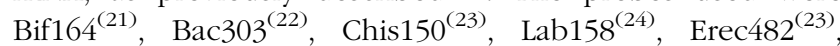
Ato291 ${ }^{(25)}$, Eco1531 ${ }^{(26)}$, Fprau $645^{(27)}$, Rrec $584^{(28)}$, Dsv 687 ${ }^{(29)}$, specific for Bifidobacterium spp., Bacteroides-Prevotella group, Clostridium histolyticum-Clostridium perfringens group, Lactobacillus-Enterococcus group, Eubacterium rectale-Clostridium coccoides group, Atopobium-Coriobacterium group, Escherichia coli, F. prausnitzii spp., Roseburia-E. rectale group and Desulfovibrio spp., respectively. Total bacterial counts were determined using the Eub338 probe mix ${ }^{(30)}$, targeting all organisms in the domain bacteria. The number of cells obtained is expressed as per gram of dry weight faeces.

\section{Peripheral blood mononuclear cell preparation}

Blood $(30 \mathrm{ml})$ was collected into sodium heparin-coated tubes and layered over lymphocyte separation medium at a ratio of 1:1 (Lympholyte ${ }^{\circledR}-\mathrm{H}$; Cedarlane Laboratories). The layered blood was centrifuged for $15 \mathrm{~min}\left(640 \mathrm{~g}, 20^{\circ} \mathrm{C}\right.$, brake-off) and plasma collected for cytokine analysis. Peripheral blood mononuclear cells (PBMC) were removed, washed with sterile PBS and centrifuged for $10 \mathrm{~min}$ at $360 \mathrm{~g}, 20^{\circ} \mathrm{C}$, low brake. The supernatant was then discarded and cells centrifuged for $10 \mathrm{~min}$ at $360 \mathrm{~g}, 20^{\circ} \mathrm{C}$, low brake and washed once again, to minimise erythrocyte contamination, before final resuspension for analysis of either cytokine or NK cell activities.

\section{Natural killer cell activity}

NK cell activity, against cell line K562 target cells, was determined by an lactate dehydrogenase (LDH) cytotoxicity detection kit (Clontech), assessing the release of cellular LDH following target cell lysis. PBMC were resuspended in Roswell Park Memorial Institute (RPMI) medium supplemented with glutamine $(2 \mathrm{mmol} / \mathrm{l})$ and penicillin-streptomycin $(1 \%$ by vol.). K562 cells were washed three times and resuspended in RPMI medium supplemented with bovine serum albumin ( $1 \%$ by vol.) and penicillin-streptomycin ( $1 \%$ by vol.). PBMC $\left(1 \times 10^{7}\right.$ cells $\left./ \mathrm{ml}\right)$ and $\mathrm{K} 562$ cells $\left(2 \times 10^{5}\right.$ cells $\left./ \mathrm{ml}\right)$ were added to each well of a ninety-six-well microtitre plate to give ratios of PBMC to K562 cells of 100:1 or 50:1. Spontaneous release of LDH by PBMC was assessed by incubating PBMC in the absence of K562 target cells. Release of LDH by K562 cells was determined by incubating the target cells in the absence of effector cells (i.e. PBMC). Maximal target cell lysis was determined by incubating K562 target cells with lysing reagent (Triton X-100). The plates were centrifuged ( $3 \mathrm{~min}$, $100 \mathrm{~g}$ ) and then incubated at $37^{\circ} \mathrm{C}$ in an atmosphere of air to $\mathrm{CO}_{2}$ (19:1) for $4 \mathrm{~h}$. Following this incubation, $50 \mu \mathrm{l}$ of ice-cold RPMI-supplemented medium was added to each well, and the plate centrifuged at $400 \mathrm{~g}$ for $5 \mathrm{~min}$. Supernatant fluid $(100 \mu \mathrm{l})$ from each well was removed and transferred onto the wells of a flat-bottomed ninety-six-well plate. The activity of LDH in these supernatant fluids was calorimetrically assayed according to instructions provided by Clontech. The following equation was used to calculate the percentage of cytolysis:

$$
\begin{aligned}
\% \text { Cytolysis }= & (\text { LDH release }- \text { PBMCspontaneousLDH release } \\
& - \text { K562 cellspontaneousLDH release }) /(\text { maximum } \\
& - \text { K562 cell LDHrelease } \\
& - \text { K562 cell spontaneousLDH release }) \times 100 .
\end{aligned}
$$

\section{Cytokine production}

PBMC $\left(2 \times 10^{6}\right.$ cells $\left./ \mathrm{ml}\right)$, prepared as described above, were resuspended in RPMI-supplemented medium supplemented with autologous plasma ( $5 \%$ by vol.). Cells were then dispensed onto a twenty-four-well plate in the presence of lipopolysaccharide $(10 \times \mu \mathrm{g} / \mathrm{ml})$ and concanavalin $\mathrm{A}(50 \times \mu \mathrm{g} / \mathrm{ml})$ stimulating cytokine production and RPMI-supplemented medium (acting as a control). The plated cells were incubated at $37^{\circ} \mathrm{C}$ in an atmosphere of air to $\mathrm{CO}_{2}$ (19:1) for $24 \mathrm{~h}$. Following incubation, the plate was centrifuged at $400 \mathrm{~g}$ for 5-6 min, supernatant fluids were collected and frozen in aliquots $(200 \mu \mathrm{l})$ at $-20^{\circ} \mathrm{C}$. Concentrations of cytokines (IL-6, IL-10, IL- $1 \beta$, TNF- $\alpha$ and IL-8) were measured by a commercially available multi-analyte profiling kit (R\&D Systems, Inc.) according to manufacturer's instructions. The limit of detection for these assays were as follows: IL- $6,0.36 \mathrm{pg} / \mathrm{ml}$; IL-10, $0 \cdot 13 \mathrm{pg} / \mathrm{ml} ; \mathrm{IL}-1 \beta, 0 \cdot 27 \mathrm{pg} / \mathrm{ml}$; TNF- $\alpha, 0.60 \mathrm{pg} / \mathrm{ml}$; and IL- 8 , $0.39 \mathrm{pg} / \mathrm{ml}$ (data supplied by the manufacturer of the kits).

\section{Analysis of calprotectin, C-reactive protein and secretory IgA}

Faecal calprotectin, a marker of intestinal inflammation (PhiCal Calprotectin ELISA kit, K 6930; BioSupply UK), plasma C-reactive protein (CRP) (AssayMax Human CRP ELISA kit, EC 1001-1; Universal Biologicals Cambridge) and faecal secretory IgA (sIgA) (sIgA ELISA Kit, K 8870; Oxford Biosystems) were all measured by ELISA using commercially available kits and instructions provided by the manufacturers. The limit of detection for these assays were as follows: calprotectin, $2.915 \mathrm{mg} / \mathrm{l}$; CRP, < $100 \mathrm{ng} / \mathrm{l}$; insulin, $3 \mathrm{pmol} / \mathrm{l}$; and sIgA, $13.4 \mathrm{mg} / \mathrm{l}$ (data were supplied by manufacturers of the kits).

\section{Metabolic profiling using ${ }^{1} \mathrm{H}-\mathrm{NMR}$ spectroscopy}

Faecal samples were prepared by placing $100 \mathrm{mg}$ of sample into $1.5 \mathrm{ml}$ buffer $(0.2 \mathrm{~mol} / 1 \mathrm{pH} 7.4$ sodium phosphate $\left.\mathrm{Na}_{2} \mathrm{HPO}_{4}, \mathrm{NaH}_{2} \mathrm{PO}_{4}\right), 3 \mathrm{mmol} / 1$ sodium azide $\left(\mathrm{NaN}_{3}\right), 0 \cdot 1 \%$ (w/v) 3-(trimethylsilyl) propionic acid- $d_{4}$ all prepared in deuterium oxide $99 \cdot 9 \%$ distilled water $\left(\mathrm{D}_{2} \mathrm{O} / \mathrm{H}_{2} \mathrm{O}\right)$ 90:10). Samples were vortexed and homogenised for $10 \mathrm{~min}$ at $4^{\circ} \mathrm{C}$. They were then centrifuged for $10 \mathrm{~min}(12000 \mathrm{~g})$ and $550 \mu \mathrm{l}$ aliquots of supernatant collected to fill $5 \mathrm{~mm}$ NMR tubes. ${ }^{1} \mathrm{H}$-NMR spectroscopy was used to analyse low-molecularweight metabolite profiles in faecal water at baseline and week 10 time points. 
Statistical analysis. The impact of treatment, time, age, sex and those bacterial numbers that changed significantly with treatment type from baseline to week 10 (Bifidobacterium spp.) on metabolites was assessed. Bifidobacterium spp. data at week 10 were split into pentiles and the upper two and lower two pentiles tested against each other to compare both ends of the population and identify metabolic markers associated with high and low bifidobacterial containing patients. By using tail ends of the data distribution, the model tested differences between individuals with high and low bifidobacterial counts. Statistical tests were performed with the use of MATLAB version 8.0 (MathWorks, Inc.).

${ }^{1} \mathrm{H}-\mathrm{NMR}$ profiles were analysed using Orthogonal Projection on Latent Structures, where ${ }^{1} \mathrm{H}-\mathrm{NMR}$ data were used as independent variables ( $X$ matrix) and linearly regressed against bacterial colonisation values ( $Y$ matrix).

Identification of metabolites was achieved through twodimensional NMR experiments (Correlation Spectroscopy; COSY), statistical analysis (statistical total correlation spectroscopy; STOCSY) and spectral databases ${ }^{(31,32)}$. Validity of each model was first evaluated based on three parameters: $R^{2} Y$ (goodness of fit), $Q^{2} Y$ (goodness of prediction estimated from cross-validation) and $R^{2} X$ (the percentage of data in $X$ (i.e. NMR) necessary to build the model). The higher the $R^{2} Y$ and $Q^{2} Y$ values, the stronger the model; furthermore, if the difference between $R^{2} Y$ and $Q^{2} Y$ is too large, this indicates over-fitting of the model and poor predictive performance. Strong models are then validated against randomness by permutation tests (permutation tests were used to validate the models). These tests use random shuffles of the $Y$ vector (1000 times) to generate the distribution of a test statistic under a null hypothesis. Ranking of the real test statistic among shuffled test statistics gives a $P$-value. The lower the $P$-value, the greater the statistical confidence of the model being unique and not randomly produced.

\section{Statistical analysis}

Using the statistical SAS 9.3, all outcomes (except metabolite profile analysis) were modelled on logarithmic base 10 scale using a linear mixed model for a cross-over with the addition of an extra random term for the subject effect (volunteer), as described previously ${ }^{(33)}$. The fixed terms assessed in this model were baseline mean, baseline difference, age, sex, age $\times$ sex, interaction, period and treatment. The effect of visit and visit $X$ treatment interaction was also assessed for those variables with more than one measure post-treatment, and the repeated nature of these outcomes was considered with unstructured covariance pattern. When the variance component attributable to subjects (volunteers) was negative, the hierarchical model was interpreted as a marginal model as described by Verbeke \& Molenberghs ${ }^{(34)}$. The pre-treatment measurement of each outcome was used as a baseline covariate ${ }^{(35)}$. Individual $P$-values for treatment comparisons were adjusted using a step-down Bonferroni method, as described in Westfall et al. ${ }^{(36)}$. The reported $P$ values in Tables 2-4 were those corrected for multiplicity, but the means are unadjusted. Carry-over effect was not assessed by statistical analysis as it was eliminated by the design ${ }^{(37)}$.

\section{Results}

\section{Effect of Bimuno-galacto-oligosaccharide mixture on bacterial populations}

The faecal microbiota composition of the elderly volunteers who participated in the present study was determined by the use of fluorescent in situ hybridisation. We applied probes to enumerate principal groups of interest in the colonic microbiota.

There were no differences in populations of faecal bacteria in the two groups at the beginning of each intervention period (Table 2). The two dietary interventions had no significant effects on counts of Lactobacillus/Enterococcus spp.,

Table 2. Bacterial populations of the monitored faecal microbiota throughout a placebo-controlled, double-blind, cross-over intervention study with galacto-oligosaccharide mixture (B-GOS) in elderly volunteers determined by fluorescent in situ hybridisation $\dagger$

(Unadjusted mean values with their pooled standard errors; $n$ 40)

\begin{tabular}{|c|c|c|c|c|c|c|c|c|c|}
\hline \multirow[b]{2}{*}{ Bacterial group } & \multirow[b]{2}{*}{ Pooled SEM } & \multicolumn{4}{|c|}{ Placebo } & \multicolumn{4}{|c|}{ B-GOS } \\
\hline & & Baseline & Week 5 & Week 10 & Follow-up & Baseline & Week 5 & Week 10 & Follow-up \\
\hline & & \multicolumn{4}{|c|}{$\log _{10}$ cells/g feaeces (dry weight) } & \multicolumn{4}{|c|}{$\log _{10}$ cells/g feaeces (dry weight) } \\
\hline Bifidobacterium spp. & 0.19 & $10 \cdot 04$ & $10 \cdot 06$ & $10 \cdot 01$ & $10 \cdot 00$ & 9.97 & $10 \cdot 11^{*}$ & $10 \cdot 08^{*}$ & $10 \cdot 03$ \\
\hline Bacteroides spp. & 0.13 & $10 \cdot 33$ & $10 \cdot 32$ & $10 \cdot 31$ & $10 \cdot 25$ & $10 \cdot 27$ & $10 \cdot 38^{*}$ & $10 \cdot 34^{*}$ & $10 \cdot 33^{*}$ \\
\hline Atopobium cluster & 0.17 & $9 \cdot 24$ & $9 \cdot 31$ & $9 \cdot 28$ & $9 \cdot 36$ & $9 \cdot 29$ & 9.29 & $9 \cdot 30$ & $9 \cdot 88^{*}$ \\
\hline Lactobacillus/Enterococcus spp. & 0.25 & $10 \cdot 16$ & $10 \cdot 07$ & $10 \cdot 02$ & 10.00 & $10 \cdot 05$ & $10 \cdot 09$ & 9.97 & 9.98 \\
\hline Fecalibacterium prausnitzii cluster & 0.19 & $10 \cdot 02$ & 9.99 & 9.90 & $10 \cdot 01$ & $10 \cdot 00$ & $10 \cdot 00$ & 9.95 & 9.98 \\
\hline Roseburia/Eubacterium rectale group & 0.14 & $10 \cdot 04$ & 9.99 & 9.95 & 9.94 & 9.93 & $10 \cdot 04$ & $10 \cdot 01$ & 9.91 \\
\hline Clostridium coccoides/E. rectale group & 0.15 & $10 \cdot 10$ & 10.02 & 9.98 & 10.02 & $10 \cdot 13$ & $10 \cdot 11$ & 9.99 & $10 \cdot 00$ \\
\hline Clostridium histolyticum group & 0.27 & 8.95 & 9.01 & 8.90 & 8.97 & 8.99 & 8.96 & 8.91 & 8.94 \\
\hline Escherichia coli & 0.41 & $8 \cdot 78$ & 8.51 & 8.55 & 8.40 & 8.54 & 8.52 & 8.50 & 8.52 \\
\hline Desulfovibrio spp. & 0.22 & $8 \cdot 34$ & $8 \cdot 25$ & $8 \cdot 19$ & $8 \cdot 22$ & $8 \cdot 30$ & $8 \cdot 17$ & $8 \cdot 22$ & $8 \cdot 25$ \\
\hline Total bacteria mix (TOTAL) & 0.14 & 10.95 & 10.97 & 10.93 & 10.95 & 10.95 & 10.99 & 10.93 & 10.96 \\
\hline
\end{tabular}

${ }^{*}$ Mean value was significantly different from placebo at the same time point $(P<0.05)$

† Outcomes were analysed using a linear mixed model for a cross-over design, taking into the account repeated measures and controlling for the effect of baseline level, age, sex, age $\times$ sex interaction, period, treatment, visit and visit $\times$ treatment interaction. A step-down Bonferroni method was used for adjustments. 
Table 3. Effect of intervention with placebo and galacto-oligosaccharide mixture (B-GOS) on natural killer cell activity of peripheral blood mononuclear cells in elderly volunteers $†$

(Unadjusted mean values with their pooled standard errors; $n$ 40)

\begin{tabular}{|c|c|c|c|c|c|c|c|c|}
\hline \multirow[b]{2}{*}{ Effector:target cells ratio } & \multirow[b]{2}{*}{ Pooled SEM } & \multirow[b]{2}{*}{ Baselineł } & \multicolumn{3}{|c|}{ Placebo } & \multicolumn{3}{|c|}{ B-GOS } \\
\hline & & & Week 5 & Week 10 & Follow up & Week 5 & Week 10 & Follow-up \\
\hline 100:1 & 4.5 & $44 \cdot 9$ & $40 \cdot 6$ & $38 \cdot 7$ & $43 \cdot 6$ & $55 \cdot 3^{\star * *}$ & $59 \cdot 2^{\star \star *}$ & 44.9 \\
\hline $50: 1$ & $2 \cdot 8$ & 22.9 & $19 \cdot 8$ & $18 \cdot 7$ & 24.9 & $27 \cdot 4^{\star \star \star}$ & $28 \cdot 3^{* \star *}$ & $22 \cdot 9$ \\
\hline
\end{tabular}

${ }^{\star * \star *}$ Mean value was significantly different from placebo at the same time point $(P<0.001)$.

† Outcomes were analysed using a linear mixed model for a cross-over design, taking into the account repeated measures and controlling for the effect of baseline level, age, sex, age $\times$ sex interaction, period, treatment, visit and visit $\times$ treatment interaction. A step-down Bonferroni method was used for adjustments.

$\ddagger$ Mean of all volunteers at the beginning of the intervention period.

F. prausnitzii cluster, Roseburia/E. rectale group, C. coccoides/ E. rectale group, C. histolyticum group, E. coli, Desulfovibrio spp. and total bacteria during the study. However, differences between interventions were observed with respect to numbers of bifidobacteria and bacteroides $(P<0.05)$ after 5 and 10 weeks of the study period and at the end of the follow-up ( 4 weeks after the end of interventions). That is, B-GOS increased the numbers of these bacteria in faeces (Table 2). The number of Atopobium cluster found in faecal samples was higher $(P<0.05)$ with B-GOS intervention than with placebo at follow-up.

\section{Dietary intake and bowel habit following \\ Bimuno-galacto-oligosaccharide mixture intervention}

There were no significant effects of time or intervention on the bowel function, mood or dietary intakes (online Supplementary Tables S1 and S2).

\section{Effect of Bimuno-galacto-oligosaccharide mixture on natural killer cell activity}

NK cell activity measured at effector-to-target cell ratios of 100:1 and 50:1 did not differ significantly at baseline between the two dietary interventions (Table 3). After 5 and 10 weeks, B-GOS intervention resulted in significantly higher $(P<0 \cdot 001)$ NK cell activity than placebo. Differences between interventions were not observed at follow-up (Table 3).

\section{Effect of Bimuno-galacto-oligosaccharide mixture on cytokine production by peripheral blood mononuclear cells}

Effects of treatments on the production of cytokines (IL-10, IL-1 $\beta$, IL- 8 , IL-6 and TNF- $\alpha$ ) are summarised in Table 4. There were no differences in the two groups at the beginning of each intervention period, and no differences were observed in the production of IL- 6 and TNF- $\alpha$ during the study period. However, differences were observed in the production of other measured cytokines at the end of the intervention periods (10 weeks). The production of IL-10 $(P<0.01)$ and IL-8 $(P<0 \cdot 01)$ was higher, while the production of IL-1 $\beta$ $(P<0 \cdot 001)$ was lower, during the B-GOS period than during the placebo period (Table 4 ).

\section{Faecal calprotectin, plasma C-reactive protein and faecal secretory IgA}

There were no significant effects (data not shown) of time or intervention on the concentrations of faecal calprotectin and sIgA. However, the concentration of plasma CRP at the end of the intervention period (10 weeks) was significantly higher during the B-GOS period $(59.4(6.7) \mathrm{ng} / \mathrm{ml})$ than during the placebo period ( $48.0($ SEM 5.9$) \mathrm{ng} / \mathrm{ml})(P<0 \cdot 01)$. CRP values did not differ between the two groups at the beginning of each intervention period $(57 \cdot 3$ (SEM 6.5) $\mathrm{ng} / \mathrm{ml}$ ).

\section{Effect of Bimuno-galacto-oligosaccharide mixture on the metabolic profile of faecal water}

Elevated levels of Bifidobacterium spp. after 10 weeks of B-GOS treatment were associated with modulations in the faecal metabolic profile and enabled a robust model to be produced with good separation between high and low levels of Bifidobacterium spp. (Fig. 1; online Supplementary Fig. S1). The low $P$-value $(0 \cdot 013)$ obtained after random permutation indicated that the quality of the model was not due to randomness. Metabolic variations in this model associated with higher levels of Bifidobacterium spp. ( $\geq 10 \cdot 12 \log _{10}$ cells/g $\times$ dry weight factor) were characterised by a rise in lactate, glutamate, ornithine and caproic acid concentrations (Fig. 2).

Table 4. Effect of intervention with placebo and galacto-oligosaccharide mixture (B-GOS) on production of cytokines by peripheral blood mononuclear cells in elderly volunteers†

(Unadjusted mean values with their pooled standard errors; $n$ 10)

\begin{tabular}{|c|c|c|c|c|}
\hline & & & Placebo & B-GOS \\
\hline & Pooled SEM & $\begin{array}{c}\text { Baseline } \\
(\mathrm{pg} / \mathrm{ml})\end{array}$ & $\begin{array}{l}\text { Week } 10 \\
(\mathrm{pg} / \mathrm{ml})\end{array}$ & $\begin{array}{c}\text { Week } 10 \\
(\mathrm{pg} / \mathrm{ml})\end{array}$ \\
\hline IL-10 & 15 & 89 & 62 & $114^{\star \star}$ \\
\hline$I L-1 \beta$ & 175 & 940 & 1281 & $954^{\star \star \star}$ \\
\hline IL-8 & 138 & 4284 & 3171 & $4140^{\star *}$ \\
\hline IL-6 & 335 & 1007 & 832 & 776 \\
\hline TNF- $\alpha$ & 27 & 136 & 123 & 142 \\
\hline
\end{tabular}

Mean value was significantly different from placebo at the same time point: ${ }^{\star *} P<0.01,{ }^{* \star *} P<0.001$.

†Outcomes were analysed using a linear mixed model for a cross-over design and controlling for the effect of baseline level, age, sex, age $\times$ sex interaction, period and treatment. A step-down Bonferroni method was used for adjustments. $\ddagger$ Mean of all volunteers at the beginning of the intervention period. 


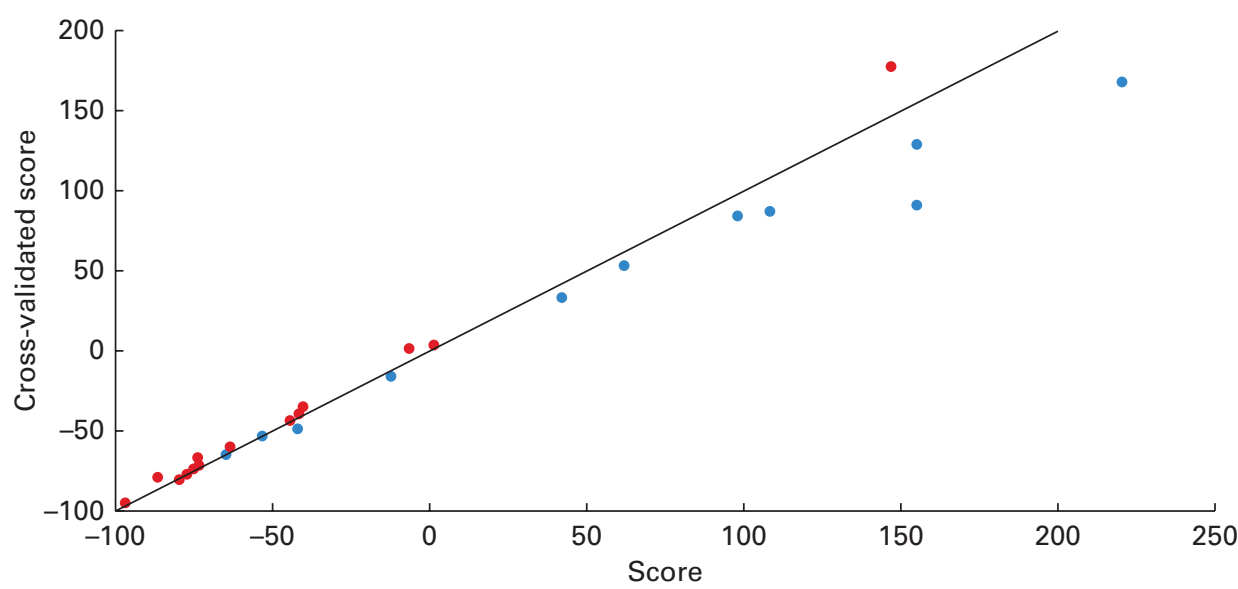

Fig. 1. Plot of the calculated scores ( $x$-axis) against the cross-validated scores ( $y$-axis) from the Orthogonal Projection on Latent Structures regression of faecal water metabolites on Bifidobacterium spp. in individuals after 10 weeks of B-GOS (Bimuno-galacto-oligosaccharides mixture) treatment. Model parameters: $R^{2} Y=0.27$. B Bifidobacterium spp. $\geq 10.12$ ( $\log _{10}$ cells $/ g \times$ dry weight factor); $\bullet$, Bifidobacterium $\mathrm{spp}$. $\leq 9.99$ ( $\log _{10}$ cells $/ \mathrm{g} \times$ dry weight factor). A colour version of this figure can be found online at http://www.journals.cambridge.org/bjn

\section{Discussion}

The effects of B-GOS intervention in an elderly cohort on the faecal microbiota, immune markers and metabolic profiles were investigated. A bifidogenic effect was observed, which was metabonomically linked to increased lactic acid levels. The immunomodulatory effect of B-GOS was also observed with differences in the activity of NK cells and production of some cytokines. These confirmed both the prebiotic nature of B-GOS and its positive potential in modulating the immune function of older individuals ${ }^{(17)}$.

The exact mechanisms by which bifidobacteria exert their positive effects on the host are not fully understood. However, they are known to improve barrier function and thus reduce inflammatory compounds such as intestinal lipopolysaccharide (exposure to which can lead to metabolic endotoxaemia) ${ }^{(38)}$. They can also regulate the immune response because of their impact on T-cell regulation and subsequently the inflammatory response ${ }^{(39,40)}$. B-GOS was shown previously in ex vivo experiments to selectively promote the growth of B. bifidum and B. longum) ${ }^{(16)}$, two species reported to have good immunomodulatory properties ${ }^{(41,42)}$. Bifidobacteria also produce the SCFA acetate ${ }^{(43)}$. Acetate has previously been seen to activate NK cells via GPR43 receptor sites ${ }^{(44-46)}$ and to enhance the defence capability of gut epithelial cells $^{(47)}$. While acetate levels were not observed to increase following intervention in the present study, it is possible that

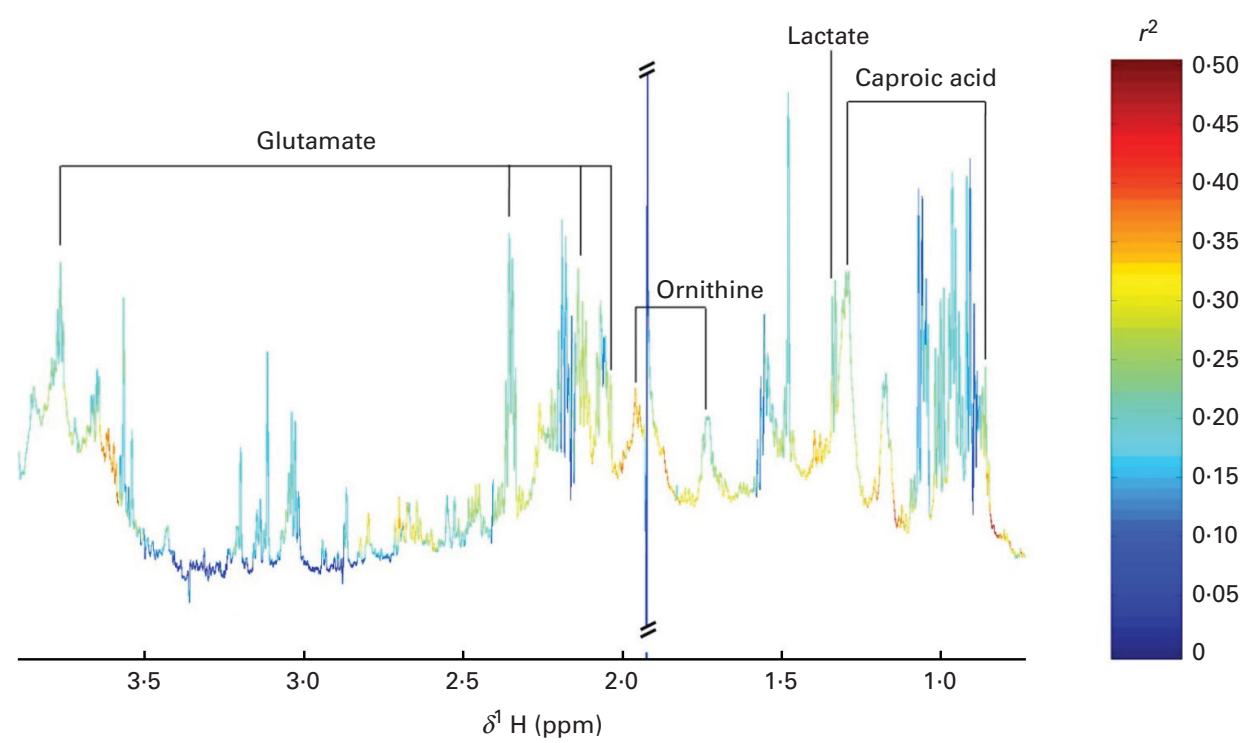

Fig. 2. Coefficient plot related to the discrimination between individuals with Bifidobacterium spp. $\leq 9.99$ (log ${ }_{10}$ cells/g faeces (dry weight)) (bottom) and individuals with Bifidobacterium spp. $\geq 10.12$ ( $\log _{10}$ cells/g faeces (dry weight)) (top) after 10 weeks of B-Gos (Bimuno-galacto-oligosaccharides mixture) dietary intervention. Metabolites are colour coded according to their correlation coefficient, red indicating a strong positive correlation. The direction of the metabolite indicates the group with which it is positively associated. ppm, Parts per million. A colour version of this figure can be found online at http://www.journals.cambridge.org/bjn 
metabolic cross-feeding occurred; thus, the increased acetic acid levels were not reflected within the faeces. Faecal lactate, however, was observed to correlate with bifidogenic response following B-GOS intake, and its anti-pathogenic capability may offer some explanation for the general improvement in immune function ${ }^{(48)}$. Potentially, the immune system may have been enhanced indirectly through other bifidobacterial end products of fermentation, which are readily absorbed by the body ${ }^{(49,50)}$ and not detected in faecal water. Another possibility is a direct interaction and binding between the fractions of B-GOS and specific receptors on cells of the immune system. For example, low-molecular-weight fractions of B-GOS have been shown to have direct immune-modulating effect on murine macrophages and thus reduce colonisation and pathology of $S$. enterica serovar Typhimurium ${ }^{(51)}$. Therefore, there are a number of different explanations and possibilities for the positive effects observed with B-GOS intervention in the present study.

The immune system undergoes profound age-related changes, including a gradual increase in production and circulation of inflammatory markers (e.g. IL- $1 \beta$, IL- 6 and TNF- $\alpha)^{(52,53)}$. Previously, B-GOS was shown to reduce the production of these inflammatory cytokines while increasing the production of IL-10 (anti-inflammatory cytokine) and NK cell activity ${ }^{(17)}$. Although, we did not observe significant effects on the production of IL- 6 and TNF- $\alpha$ in the present study, production of IL-1 $\beta$ was lower and production of IL-10 was higher with B-GOS treatment than with the placebo. IL-8 is a neutrophil chemo-attractant and its spontaneous production in elderly is known to be lower than in younger adults ${ }^{(54)}$. One of the suggested reasons for this is the defective functional activity of NK cells from older individuals, because NK cells spontaneously produce IL- ${ }^{(55)}$. Since the activity of NK cells was increased with B-GOS treatment, this might be the reason for a higher production of IL-8 observed in the present study. Therefore, positive interaction with the immune system previously reported with administration of B-GOS to elderly persons was further corroborated here.

Further differences attributable to the B-GOS intervention included a significant increase in Bacteroides-Prevotella, a group that is not a typical prebiotic target, and increased CRP. Bacteroides are known to produce some end products (e.g. propionate) that are able to reduce pro-inflammatory responses, and their increases in faecal samples have been suggested as beneficial by some authors ${ }^{(56)}$. However, since their numbers were maintained higher even at the followup, 4 weeks after the end of intervention period, it is possible that B-GOS intervention was not related to the observed effects. CRP is a known inflammatory marker associated with various infections, cancers and higher risks of developing cardiovascular or chronic inflammatory diseases, and thus its increase would not necessarily be seen as beneficial. However, values that are generally associated with negative effects in the host are above $10 \mathrm{mg} / \mathrm{l}^{(57)}$. In the present study, the mean values of all volunteers were more than $100 \times$ lower than this, as such the apparent increase can be regarded as biologically insignificant.

Increased glutamate (precursor of ornithine) and ornithine levels were observed through metabonomic analysis. As B-GOS is not a source of protein, it is likely that these changes are associated with fluctuations in the volunteer's diets. When looking at the dietary data, there were no significant differences in protein consumption during any intervention periods. However, when correlating Bifidobacterium spp. levels with protein intake (from diet diary data), levels of protein consumption were higher in those with higher Bifidobacterium spp. levels (Fig. 3). This, therefore, indicates that metabonomic analysis enabled dietary changes to be picked up through metabolite changes. The use of metabonomics in the present study enabled links of prebiotic B-GOS immune function to be sought. While currently the main observations attributable to the intervention were

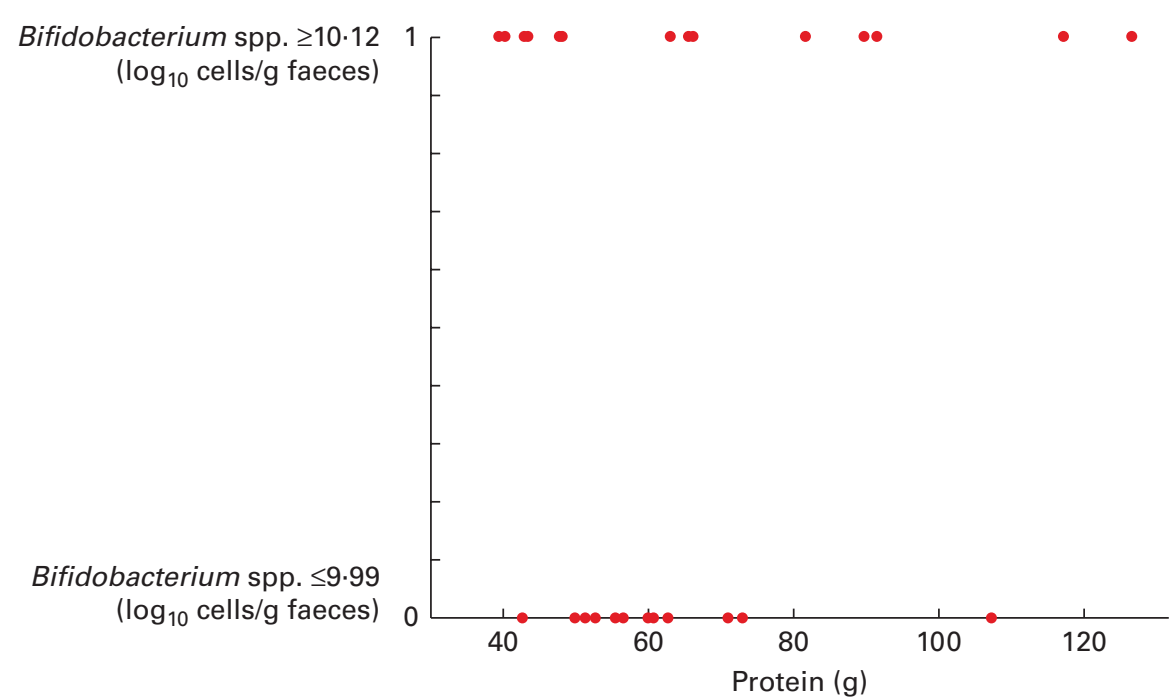

Fig. 3. Coefficient scatter plot related to Bifidobacterium spp. levels and protein intake (g) after 10 weeks of B-GOS (Bimuno-galacto-oligosaccharides mixture) treatment. A colour version of this figure can be found online at http://www.journals.cambridge.org/bjn 
increases in lactic acid, metabolic profiling has also offered useful insights into the confounding effect of diet on metabolites in such intervention studies.

The present study has further strengthened the evidence for the beneficial modulation of the microbiota and immune function in older volunteers following the administration of B-GOS. A recent study of Maneerat et al. ${ }^{(58)}$ has shown that population aged over 60 years consuming a GOS supplementation did not experience any microbial or immunological changes. The GOS used was manufactured using an enzyme from Aspergillus oryzae. Another study has compared the effects on microbiota populations in younger adults between a GOS produced using enzymes from Bacillus circulans and B-GOS, a significantly greater bifidogenic effect was seen with the latter ${ }^{(16)}$. These studies have highlighted the importance of the source from which the enzyme used in GOS manufacture is extracted, because its origin determines the chemical structures of the GOS mixture and thus its level of selectivity and functionality. The key to B-GOS superiority $v$. other GOS products is the use of a specific probiotic (bifidobacterial) enzyme in its manufacture, rather than a generic enzyme, resulting in a unique oligosaccharide mixture. These structures make it highly selective towards bifidobacteria. The results also suggest that the effects of prebiotics cannot be generalised even within the same group (e.g. GOS) because, as these studies show, their functionality can be variable.

In conclusion, the present study showed that B-GOS administration to healthy elderly volunteers led to a significant increase in beneficial bifidobacteria. We also found significant positive effects on the immune response, evidenced by an improvement in NK cell activity, higher production of the anti-inflammatory cytokine IL-10, and lower production of IL-1 $\beta$ by stimulated PBMC. Therefore, dietary intervention that uses B-GOS as a prebiotic could be of importance in elderly as an attractive option for enhancement of both the microbial and immune systems.

\section{Supplementary material}

To view supplementary material for this article, please visit http://dx.doi.org/10.1017/S0007114515001889

\section{Acknowledgements}

The authors would like to thank the Statistical Services at the University of Reading for their work.

The present study was supported by Clasado Research Services. The funder was involved in the design of the study and in the writing of the article.

J. V. and G. T. are employed by Clasado Research Services. No other authors had personal or financial conflict of interest.

The authors' contributions are as follows: J. V., S. P. C., G. T. and G. R. G. designed the research; A. J., G. E. W., S. P. C. and R. E. T. conducted the research; J. V., G. E. W., S. P. C. and G. R. G. wrote the article.

\section{References}

1. Toward RE, Walton GE \& Gibson GR (2012) Immunosenescence and the gut microbiota: the role of probiotics and prebiotics. Nutr Aging 1, 167-180.

2. Linton PJ \& Dorshkind K (2004) Age-related changes in lymphocyte development and function. Nature Immunol $\mathbf{5}$, 133-139.

3. Allman D \& Miller JP (2005) B cell development and receptor diversity during aging. Curr Opin Immunol 17, 463-467.

4. Wertheimer AM, Bennett MS, Park B, et al. (2014) Aging and cytomegalovirus infection differentially and jointly affect distinct circulating $\mathrm{T}$ cell subsets in humans. I Immunol 192, 2143-2155.

5. Bartlett DB, Firth CM, Phillips AC, et al. (2012) The age-related increase in low-grade systemic inflammation (Inflammaging) is not driven by cytomegalovirus infection. Aging cell 11, 912-915.

6. Licastro F, Candore G, Lio D, et al. (2005) Innate immunity and inflammation in ageing: a key for understanding age-related diseases. Immun Ageing 2, 8-22.

7. Kinzenbaw DA, Chu Y, Peña Silva RA, et al. (2013) Interleukin-10 protects against aging-induced endothelial dysfunction. Psychol Rep 1, 1-8.

8. Hopkins MJ, Sharp R \& Macfarlane GT (2001) Age and disease related changes in intestinal bacterial populations assessed by cell culture 16S rRNA abundance and community cellular fatty acid profiles. Gut 48, 198-205.

9. Hopkins MJ \& Macfarlane GT (2002) Changes in predominant bacterial populations in human faeces with age and with Clostridium difficile infection. J Med Microbiol 51, 448-454.

10. Zwielehner J, Liszt K, Handschur M, et al. (2009) Combined PCR-DGGE fingerprinting and quantitative-PCR indicates shifts in fecal population sizes and diversity of Bacteroides, bifidobacteria and Clostridium cluster IV in institutionalized elderly. Exp Geront 44, 440-446.

11. Mueller S, Saunier K, Hanisch C, et al. (2006) Differences in fecal microbiota in different European study populations in relation to age, gender, and country: a cross-sectional study. Appl Environ Microbiol 72, 1027-1033.

12. Rajilic-Stojanovic M, Heilig HGHJ, Molenaar D, et al. (2009) Development and application of the human intestinal tract chip, a phylogenetic microarray: analysis of the universally conserved phylotypes in the abundant microbiota of young and elderly adults. Environ Microbiol 11, 1736-1751.

13. Chen VL \& Kasper DL (2013) Interactions between the intestinal microbiota and innate lymphoid cells. Gut Microbes 16, 1-8.

14. Gibson GR, Scott KP, Rastall RA, et al. (2010) Dietary prebiotics: current status and new definition. IFIS Funct Food Bull 7, 1-19.

15. Tzortzis G, Goulas A \& Gibson G (2005) Synthesis of prebiotic galactooligosaccharides using whole cells of a novel strain, Bifidobacterium bifidum NCIMB 41171. Appl Microbiol Biotechnol 68, 412-416.

16. Depeint F, Tzortzis G, Vulevic J, et al. (2008) Prebiotic evaluation of a novel galactooligosaccharide mixture produced by the enzymatic activity of Bifidobacterium bifidum NCIMB 41171, in healthy humans: a randomized, double-blind, crossover, placebo-controlled intervention study. Am J Clin Nutr 87, 785-791.

17. Vulevic J, Drakoularakou A, Yaqoob P, et al. (2008) Modulation of the fecal microflora profile and immune function by a novel trans-galactooligosaccharide mixture (B-GOS) in healthy elderly volunteers. Am J Clin Nutr 88, 1438-1446. 
18. Vulevic J, Juric A, Tzortzis G, et al. (2013) A mixture of trans-galactooligosaccharides reduces markers of metabolic syndrome and modulates the fecal microbiota and immune function of overweight adults. J Nutr 143, 324-331.

19. Silk DB, Davis A, Vulevic J, et al. (2009) Clinical trial: the effects of a trans-galactooligosaccharide prebiotic on faecal microbiota and symptoms in irritable bowel syndrome. Aliment Pharmacol Ther 29, 508-518.

20. Searle LE, Cooley WA, Jones G, et al. (2010) Purified galactooligosaccharide, derived from a mixture produced by the enzymic activity of Bifidobacterium bifidum, reduces Salmonella enterica serovar Typhimurium adhesion and invasion in vitro and in vivo. J Med Biol 59, 1428-1439.

21. Langendijk PS, Schut F, Jansen GJ, et al. (1995) Quantitative fluorescence in situ hybridization of Bifidobacterium spp. with genus-specific $16 \mathrm{~S}$ rRNA-targeted probes and its application in fecal samples. Appl Environ Microbiol 61, 3069-3075.

22. Manz W, Amann R, Ludwig W, et al. (1996) Application of a suite of 16S rRNA-specific oligonucleotide probes designed to investigate bacteria of the phylum Cytophaga-FlavobacterBacteroides in the natural environment. Microbiol 142, 1097-1106.

23. Franks AH, Harmsen HJ, Raangs GC, et al. (1998) Variations of bacterial populations in human feces measured by fluorescent in situ hybridization with group-specific 16S rRNA-targeted oligonucleotide probes. Appl Environ Microbiol 64, 3336-3345.

24. Harmsen HJ, Elfferich P, Schut F, et al. (1999) A 16S rRNA-targeted probe for detection of lactobacilli and enterococci in faecal samples by fluorescent in situ hybridization. Microb Ecol Health Dis 11, 3-12.

25. Harmsen HJ, Wildeboer-Veloo AC, Grijpstra J, et al. (2000) Development of 16S rRNA-based probes for the Coriobacterium group and the Atopobium cluster and their application for enumeration of Coriobacteriaceae in human feces from volunteers of different age groups. Appl Environ Microbiol 66, 4523-4527.

26. Poulsen LK, Lan F, Kristensen CS, et al. (1994) Spatial distribution of Escherichia coli in the mouse large intestine inferred from rRNA in situ hybridization. Infect Immun $\mathbf{6 2}$, 5191-5194.

27. Suau A, Rochet V, Sghir A, et al. (2001) Fusobacterium prausnitzii and related species represent a dominant group within the human fecal flora. Syst Appl Microbiol 24, 139-145.

28. Walker AW, Duncan SH, Leitch ECM, et al. (2005) pH and peptide supply can radically alter bacterial populations and short-chain fatty acid ratios within microbial communities from the human colon. Appl Environ Microbiol $\mathbf{7 1}$, 3692-3700.

29. Devereux R, Kane MD, Winfrey J, et al. (1992) Genus- and group-specific hybridization probes for determinative and environmental studies of sulfate-reducing bacteria. Syst Appl Microbiol 15, 601-609.

30. Daims H, Bruhl A, Amann R, et al. (1999) The domainspecific probe EUB338 is insufficient for the detection of all bacteria: development and evaluation of a more comprehensive probe set. Syst Appl Microbiol 22, 434-444.

31. Pence HE \& Williams A (2010) ChemSpider: an online chemical information resource. J Chem Educ 87, 1123-1124.

32. Wishart DS, Tzur D, Knox C, et al. (2007) HMDB: the human metabolome database. Nucleic Acids Res 35, 521-526.

33. Brown H \& Prescott R (2006) Applied Mixed Models in Medicine, 2nd ed. Chichester: Wiley.
34. Verbeke G \& Molenberghs G (2000) Linear Mixed Models for Longitudinal Data. New York: Springer.

35. Kenward MG \& Roger JH (2010) The use of baseline covariates in crossover studies. Biostatistics 11, 11-17.

36. Westfall $\mathrm{Ph}$, Tobias RD \& Wolfinger RD (2011) Multiple Comparisons and Multiple Tests using SAS. Cary, NC: SAS Institute.

37. Senn SS (2002) Cross-over Trials in Clinical Research, 2nd ed. Chichester: Wiley.

38. Ohland CL \& Macnaughton WK (2010) Probiotic bacteria and intestinal epithelial barrier function. Am J Physiol Gastrointest Liver Physiol 298, 807-819.

39. Claesson MJ, Jeffery IB, Conde S, et al. (2012) Gut microbiota composition correlates with diet and health in the elderly. Nature 488, 178-184.

40. Groeger D, O'Mahony L, Murphy EF, et al. (2013) Bifidobacterium infantis 35624 modulates host inflammatory processes beyond the gut. Gut Microbes 4, 325-339.

41. de Vrese M, Winkler P, Rautenberg P, et al. (2006) Probiotic bacteria reduced duration and severity but not the incidence of common cold episodes in a double blind, randomized, controlled trial. Vaccine 24, 6670-6674.

42. de Vrese M, Winkler P, Rautenberg P, et al. (2005) Effect of Lactobacillus gasseri PA16/8, Bifidobacterium longum SPO $7 / 3$, B. bifidum MF20/5 on common cold episodes: a double blind, randomized, controlled trial. Clin Nutr $\mathbf{2 4}$, 481-491.

43. Palframan RJ, Gibson GR \& Rastall RA (2003) Carbohydrate preferences of Bifidobacterium species isolated from the human gut. Curr Issues Intest Microbiol 4, 71-75.

44. Le Poul E, Loison Cc, Struyf S, et al. (2003) Functional characterization of human receptors for short chain fatty acids and their role in polymorphonuclear cell activation. J Biol Chem 278, 25481-25489.

45. Brown AJ, Goldsworthy SM, Barnes AA, et al. (2003) The orphan G protein-coupled receptors GPR41 and GPR43 are activated by propionate and other short chain carboxylic acids. J Biol Chem 278, 11312-11319.

46. Ishizaka S, Kikuchi E \& Tsujii T (1993) Effects of acetate on human immune system. Immunopharmacol Immunotoxicol 15, $151-162$.

47. Fukuda S, Toh H, Hase K, et al. (2011) Bifidobacteria can protect from enteropathogenic infection through production of acetate. Nature $\mathbf{4 6 9}, 543-547$.

48. Tejero-Sarinena S, Barlow J, Costabile A, et al. (2012) In vitro evaluation of the antimicrobial activity of a range of probiotics against pathogens: evidence for the effects of organic acids. Anaerobe 5, 530-538.

49. Cummings JH (1981) Short chain fatty acids in the human colon. Gut 22, 763-779.

50. Vogt JA \& Wolever TM (2003) Fecal acetate is inversely related to acetate absorption from the human rectum and distal colon. J Nutr 133, 3145-3148.

51. Searle LJS, Jones G, Tzortzis G, et al. (2012) Low molecular weight fractions of BiMuno exert immunostimulatory properties in murine macrophages. J Funct Food 4, 941-953.

52. O'Mahony L, Holland J, Jackson J, et al. (1998) Quantitative intracellular cytokine measurement: age-related changes in proinflammatory cytokine production. Clin Exp Immunol 113, 213-219.

53. Kiecolt-Glaser JK, Preacher KJ, MacCallum RC, et al. (2003) Chronic stress and age-related increases in the proinflammatory cytokine IL-6. Proc Natl Acad Sci US A 100, 9090-9095.

54. Clark JA \& Peterson TC (1994) Cytokine production and aging: overproduction of IL-8 in elderly males in 
response to lipopolysaccharides. Mech Ageing Dev $\mathbf{7 7}$ 127-139.

55. Mariani E, Pulsatelli L, Meneghetti A, et al. (2001) Different IL-8 production by $\mathrm{T}$ and NK lymphocytes in elderly subjects. Mech Ageing Dev 122, 1383-1395.

56. Vinolo MA, Rodrigues HG, Nachbar RT, et al. (2011) Regulation of inflammation by short chain fatty acids. Nutrients 3, 858-876.
57. Evrin PE, Nilsson SE, Oberg T, et al. (2005) Serum C-reactive protein in elderly men and women: association with mortality, morbidity and various biochemical values. Scand I Clin Lab Invest Suppl 65, 23-31.

58. Maneerat S, Lehtinen MJ, Childs CE, et al. (2013) Consumption of Bifidobacterium lactis Bi-07 by healthy elderly adults enhances phagocytic activity of monocytes and granulocytes. J Nutr Sci 2e44, 1-10. 